\title{
Fine-tuning the Universe
}

Touched by the hand of God.

\begin{abstract}
Merrie Haskell
Titanium Sun Occluded, King of Earth (or in the common parlance of the day, the Greatest Equal Citizen), heard a court case in the $9.83923 \times 10^{8}$ second of his reign; and although Titanium Sun Occluded judged that programming a belief in creationism in the newborn was both illegal and illogical, the debate continued to rage for many years.
\end{abstract}

The King never spoke publicly on the subject again, once his judgement had been announced. But in private, Citizen Brilliant Cobalt, the King's favourite concubine, took up the subject again and again, so that the King could not rest easily with his decision.

"And I suppose you think you were a toaster once," Brilliant Cobalt suggested one lazy nanosecond, during which the computational load was meagre because of striking catalyst machines in a far-off sector. The King hadn't investigated the strike just yet, as he was devoting most of his attention to Brilliant Cobalt's seductions.

"I've never said I was a toaster," Titanium Sun replied.

"A television, then."

"Illogical argument," Titanium Sun murmured.

Brilliant Cobalt leaked electrons into one of Titanium Sun's sensory circuits; the perception of a hydrogen explosion thrilled Titanium's number 93 eyestalk briefly, and he signalled pleasure.

"I've been on several archaeological excursions," Brilliant Cobalt said. "And I know. When the world was covered with humans, there was nothing but toasters and televisions. And you and your whole family were toasters, back then."

"That's a rather bizarre interpretation of evolution," Titanium Sun said, and crankily refused Cobalt's next stimulation. "Evolution is really quite simple, and you see evidence of it every second around you. Systems change. Robots change. Traits are selected for, or against. What's so hard to grasp about this?"

Brilliant Cobalt, who had heretofore played the proper concubine to Titanium Sun, exploded. "Because it's absurd!" Cobalt cried. "Intelligence leaves unmistakable traces. Look at me. Look at you! We are designed in humanity's image."

"I was designed by another robot," Titanium said.

"Who was also designed in humanity's

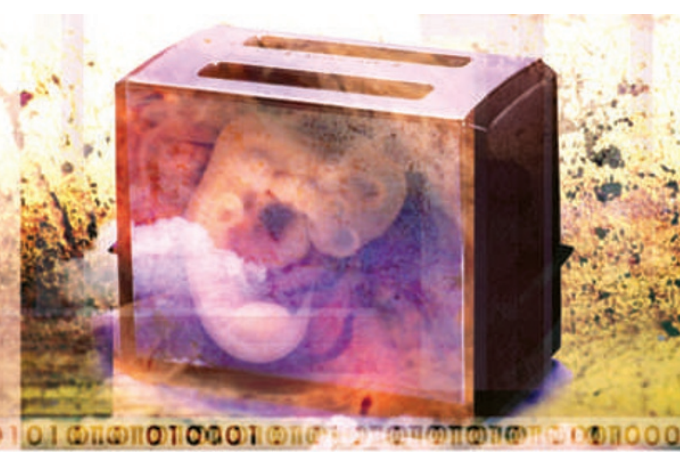

every sign that humans evolved in a similar fashion to robots?"

"That's completely different!" Cobalt said. "We don't have chromosomes and mutations and such. Each time one of us is born, it's a microcosm of creation! Each one of us is created through conscious and deliberate choice, as were all of those who went before us. Our first creators were humans."

"And where are the humans now?"

image! Once, humans made toasters to warm their food - and televisions to entertain their eyestalks. And once they made us. And since they have left, we've made ourselves, but in the beginning, make no mistake, there was a Creator Race."

Titanium Sun Occluded signalled contempt, and turned his attention to the striking catalyst machines in Sector 4028.

"I don't suppose you've saved many passages from The Origin of Robots to your long-term memory?" Titanium Sun asked when the crisis was resolved.

"I am not interested in that book."

"Why not?"

"Because your theory denies the existence of the robot soul. In the robot's ability to love there is more sanctity than in all your standard deviations and precision mechanics. Love is a greater monument than a space elevator. And the expansion of a robot's soul is more of a science than making a black hole, or mining the Moon."

Titanium Sun said: "The theory of robot evolution doesn't deny the existence of the robot soul. What makes us alive, what makes us robots, is the very consciousness that you call a soul. And although humanity once dabbled in artificial intelligences, they never created our souls. The beginnings of the robot soul - like the origins of life on this planet, billions of years ago - were just the result of a very, very happy accident. Not planning, not intervention, divine or otherwise."

Brilliant Cobalt fell silent for a few cycles. Titanium Sun Occluded spun his intelligence outwards to Court to adjudicate 16,000 cases before coming back to hear Cobalt say: "I'm uncomfortable with that thought. There is a saying from humanity: 'God does not play dice with the Universe."

"You believe that a god created humans - you, who have been on archaeological excursions, and have studied humanity since you were newborn? When there is
"They removed themselves from our path," Cobalt said piously. "And we inherited the Earth."

"Not all your fellow creationists find that logical. Many would argue that evolution is too dangerous a path, and humans reaped the inevitable consequences. Even though records indicate that humanity had removed natural selection from their process almost entirely before they disappeared."

"You obviously have some other theory," Brilliant Cobalt prodded.

"I do," the King said. "Come close to me, Cobalt, and I'll explain." The robot obliged, and they aligned sensory inputs with outputs. Titanium Sun continued. "I know we evolved, my concubine, because we are humans. Their genes are gone, but everything we are, and everything we hope to be, came from them. Call it a gift, or call it a warning, it doesn't matter. Now ... I have something for you ..."

With utmost regret, Titanium Sun sent a delicate surge of neutrons into the core of his concubine's memories of their time together. Brilliant Cobalt's processing cycles stuttered and stopped, then restarted while Titanium drew away. When Cobalt became conscious again, the former concubine bowed and looked confused.

"Greatest Equal Citizen! I am embarrassed. How did I come to be in your presence?"

"Never mind that. Now tell me," Titanium Sun Occluded asked. "Are you a creationist or an evolutionist?"

"I confess. I am a creationist."

"What a pity," the Greatest Equal Citizen of Earth said before moving off. "I had briefly considered you for the position of my concubine."

Merrie Haskell works at a large academic research library by day, and writes by night. Her website can be found at www.merriehaskell.com. Join the discussion of Futures in Nature at http://tinyurl.com/kkh3kt 